\title{
Highly Efficient Adsorption of Cd(II) onto Carboxylated Camelthorn Biomass: Applicability of Three-Parameter Isotherm Models, Kinetics, and Mechanism
}

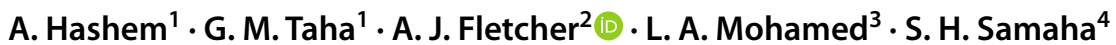

Accepted: 26 November 2020 / Published online: 7 December 2020

(c) The Author(s) 2020

\begin{abstract}
A series of malonic acid treated camelthorn (MATC) sorbents were produced via the reaction of camelthorn biomass with malonic acid, and factors affecting the extent of modification were investigated, including malonic acid concentration, dehydration time and temperature. The optimum sorbent, by carboxylic acid content, was subsequently characterised for surface charge behaviour $\left(\mathrm{pH}_{\mathrm{PZC}}\right.$ ), surface chemical functionalities (FTIR), morphological structure (SEM), and available surface area. The sorbent was subsequently utilised for adsorption of $\mathrm{Cd}(\mathrm{II})$ ions from aqueous media, and parameters influencing adsorption at $30^{\circ} \mathrm{C}$, such as sorbent dose, initial solution $\mathrm{pH}$, exposure time, metal concentration, were investigated. Isothermal analyses were performed using eight models, including two and three parameter equations, with appropriateness of fit assessed via non-linear regression analysis. The adsorption data indicated that the Langmuir model gives the most appropriate fit to experimental curves, with the models ordered as Langmuir $>$ Hill $>$ Toth $>$ Sips $>$ Jossens $>$ Khan $>$ RedlichPeterson $>$ Freundlich. The highest uptake $\left(\mathrm{q}_{\mathrm{max}}\right)$ of $582.6 \mathrm{mg} \mathrm{g}^{-1}$ was determined at $\mathrm{pH}$ 6. The Freundlich constants, $\mathrm{K}_{\mathrm{F}}$ and $\mathrm{n}$, at $30^{\circ} \mathrm{C}$ were found to be $24.94 \mathrm{mg} \mathrm{g}^{-1}$ and 2.33 , respectively. The value of $\mathrm{n}(2.33)$, being in the range $0-10$, indicates that adsorption of $\mathrm{Cd}(\mathrm{II})$ ions onto malonic acid treated camelthorn biomass is favourable. Evaluation of a series of kinetic models, allowed elucidation of the adsorption mechanism, as a pseudo-second order model gave the most appropriate fit, indicating that chemisorption processes are involved. Cd(II) ions adsorption onto MATC is enhanced by a higher level of active surface sites but was show to be independent of surface area. The work presented here indicates that this sorbent offers effective adsorption potential for $\mathrm{Cd}(\mathrm{II})$ ions from water, with potential in wastewater processing.
\end{abstract}

Keywords Camelthorn $\cdot$ Chemical modification $\cdot$ Isotherm models $\cdot$ Kinetic models

\section{Introduction}

Remediation of heavy metal species from industrial and mine wastewaters is a key challenge in reducing related water and flora contamination. Cadmium has attracted

A. J. Fletcher

Ashleigh.fletcher@strath.ac.uk

1 National Research Centre, Textile Research Division, National Research Centre, Dokki, Cairo, Egypt

2 Department of Chemical and Process Engineering, University of Strathclyde, Glasgow G1 1XJ, UK

3 Microbial Chemistry Department, National Research Centre, Dokki, Cairo, Egypt

4 Textile Metrology Department, National Institute of Standards, El-Haram, Giza, Egypt significant attention from those working in environmental remediation as a result of its high toxicity in the ionic form, which enters the environment from a number of industries $[1,2]$. Cadmium is known to bioaccumulate, being linked to renal and pulmonary issues, bone lesions, cancer, and hypertension [3]; and the World Health Organisation has mandated an upper allowable level of $3.0 \mu \mathrm{g} \mathrm{L}^{-1}$ of $\mathrm{Cd}$ (II) ions in drinking water [4]. Cadmium is easily absorbed by plants and crops such as wheat and rice. It has a strong ability to become enriched, and easily enters the body through the food chain, resulting in a hazard to human health through water, air, and plants [5]. A number of methods have been proposed for remediation of heavy metal ions from industrial effluents such as neutralisation, ion exchange, solvent extraction, photochemical degradation, electrochemical degradation, membrane separation, reverse osmosis, precipitation and adsorption [5-11], while these have been proven to 
be efficient, they are also expensive; by contrast adsorption provides an efficacious method for the remediation of heavy metal ions from water [12].

Activated carbon is often used; an efficient sorbent it is, however, also costly, therefore, a need exists for costeffective alternatives, which has motivated research into new sorbent materials, particularly those sourced from waste materials. Such a class of materials is those with lingo-cellulosic character and agricultural by-products have seen increased attention for such applications [13-16]. It has been shown that chemical modification, including incorporation of surface moieties and chemical coupling, can improve sorbent behaviour of these materials towards heavy metals [17-20].

This work aims to improve the ability of camelthorn to adsorb Cd(II) ions from water, by treatment of prepared camelthorn biomass with malonic acid to obtain malonic acid-treated camelthorn (MATC), with subsequent determination of the capacity and mechanism for adsorption of $\mathrm{Cd}$ (II) from water, evaluated through the fit of selected isothermal and kinetic models to experimentally obtained data, assessed via non-linear regression.

\section{Materials and Methods}

\section{Materials}

Camelthorn biomass utilised in this study were acquired from the Sebha desert, Libya. The lingo-cellulosic materials of camelthorn is found within the root content of this plant, hence, these were separated from the remaining organic matter, and washed with a plentiful supply of purified water to eliminate any surface particles, before subsequent drying at $80{ }^{\circ} \mathrm{C}$ for $10 \mathrm{~h}$; grinding and sieving of the resulting material, gave a final product with particle size 50-120 $\mu \mathrm{m}$. Laboratory grade chemicals were supplied by Merck, Germany: $\mathrm{Cd}\left(\mathrm{CH}_{3} \mathrm{COO}\right)_{2}$, EDTA, $\mathrm{CH}_{2}(\mathrm{COOH})_{2}, \mathrm{CH}_{3} \mathrm{COOH}$, $\mathrm{Na}_{2} \mathrm{CO}_{3},\left(\mathrm{CH}_{3}\right)_{2} \mathrm{CO}, \mathrm{NaOH}, \mathrm{HNO}_{3}$ and $\mathrm{C}_{2} \mathrm{H}_{5} \mathrm{OH}$.

\section{Preparation of the Sorbent}

MATC sorbents were prepared by adding $2 \mathrm{~g}$ of camelthorn powder to a known mass of malonic acid dissolved in water. Stirring produced a homogeneous paste, which was dried at $100-150{ }^{\circ} \mathrm{C}$, before cooling to ambient temperature. An ethanol/water mixture (80:20) was used to wash the cooled sample to remove unreacted/unwanted species. The resulting refined material was dried at $80{ }^{\circ} \mathrm{C}$ for $6 \mathrm{~h}$. Under high temperatures, malonic acid converts to the anhydride form - this reacts with hydroxyl moieties, such as those on the camelthorn residue surface to obtain the MATC sorbent, as shown in Scheme 1:
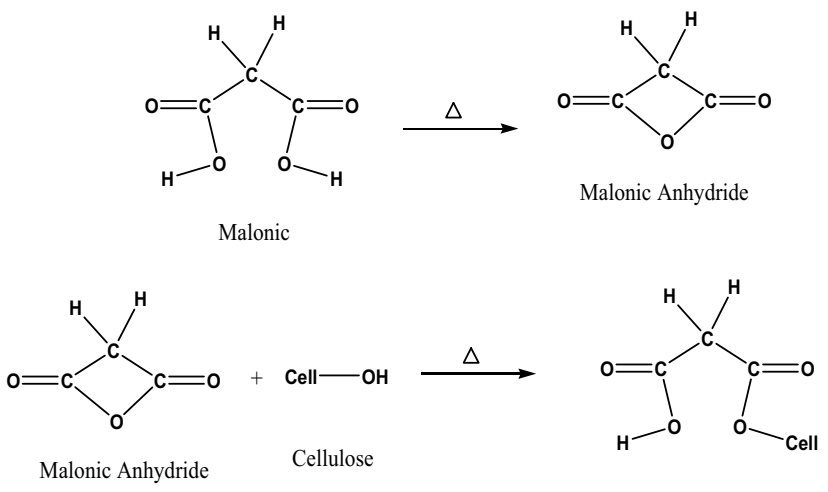

Scheme 1 Reaction of camelthorn with malonic acid, at elevated temperatures, producing malonic acid treated camelthorn sorbents

\section{Batch Adsorption Studies}

$0.03 \mathrm{~g}$ of sorbent was added to $100 \mathrm{~cm}^{3}$ of $\mathrm{Cd}\left(\mathrm{CH}_{3} \mathrm{COO}\right)_{2}$ solution $\left(0.1-1 \mathrm{~g} \mathrm{~L}^{-1}\right)$; initial $\mathrm{pH}$ was altered by dropwise addition of $0.1 \mathrm{M} \mathrm{HNO}_{3}$ or $\mathrm{NaOH}$; with the solution mixed $\left(150 \mathrm{rpm}\right.$ at $\left.30^{\circ} \mathrm{C}\right)$ before filtering to separate the sorbent and bulk solution. Pre- and post-adsorption $\mathrm{Cd}(\mathrm{II})$ ion concentrations were determined via titration with $0.0005 \mathrm{M}$ EDTA solution, and the equilibrium uptake of $\mathrm{Cd}(\mathrm{II}), \mathrm{q}_{\mathrm{e}}$ $\left(\mathrm{mg} \mathrm{g}^{-1}\right)$, determined using Eq. 1 and percentage removal calculated using Eq. 2.

$\mathrm{q}_{\mathrm{e}}=\frac{\mathrm{V}\left(\mathrm{C}_{\mathrm{o}}-\mathrm{C}_{\mathrm{e}}\right)}{\mathrm{W}}$

Removal $\%=\frac{\mathrm{C}_{\mathrm{o}}-\mathrm{C}_{\mathrm{e}}}{\mathrm{C}_{\mathrm{o}}} \times 100$

where $\mathrm{C}_{\mathrm{o}}$ and $\mathrm{C}_{\mathrm{e}}\left(\mathrm{mg} \mathrm{L}^{-1}\right)$ are initial and equilibrium Cd(II) ion concentration, $\mathrm{W}(\mathrm{g})$ is mass of sorbent used, and $\mathrm{V}(\mathrm{L})$ is $0.1 \mathrm{~L}$, i.e. $\mathrm{Cd}(\mathrm{II})$ ion solution volume.

\section{Carboxylic Acid Content}

The quantity of carboxylic acid moieties of the sorbents were determined by adding $0.2 \mathrm{~g}$ to $50 \mathrm{~cm}^{3}$ of $0.03 \mathrm{~N} \mathrm{NaOH}$. Several systems were created and allowed to equilibrate overnight at ambient temperature, after which the amount of carboxylic acid moieties were evaluated via titration $0.01 \mathrm{~N} \mathrm{HCl}$ and phenolphthalein indicator [21]. The quantity of carboxylic acid moieties of each sorbent was determined using:

$[\mathrm{COOH}] \cdot \frac{\text { meq }}{100 \text { g sample }}=\frac{\left(\mathrm{V}_{\mathrm{o}}-\mathrm{V}_{1}\right) \cdot 0.01}{\mathrm{~W}} \times 100$ 
where $\mathrm{V}_{0}$ is $\mathrm{HCl}$ volume $\left(\mathrm{cm}^{3}\right)$ consumed in a blank experiment, $\mathrm{V}_{1}$ is $\mathrm{HCl}$ volume $\left(\mathrm{cm}^{3}\right)$ consumed by the sorbent, and $\mathrm{W}$ is mass of sorbent used $(\mathrm{g})$.

\section{Characterisation of the Sorbent}

Samples of camelthorn, MATC and MATC with Cd(II) ions adsorbed were characterised using FTIR ( 2-10 mg of sorbent in $300 \mathrm{mg} \mathrm{KBr}$ to form discs analysed using a Perkin-Elmer Spectrum 1000 spectrometer, $400-4000 \mathrm{~cm}^{-1}$, interval $1 \mathrm{~cm}^{-1}$ and 120 scans) allowing assignment of vibrational frequencies associated with functional groups present on the sorbent surface, and of any interactions between the adsorbed Cd(II) ions and the sorbent surface. Sorbent surfaces were coated with chromium on carbon tape and imaged at $1000 \times$ magnification (TESCAN CE VEGA 3 SBU).Energy-dispersive X-ray (EDX) patterns were obtained to confirm the presence of metal ions on the surface post-adsorption (Oxford Instruments EDX attached to JEOL-JSM-5600). Porous characteristics were determined using $\mathrm{O}_{2}$-free $\mathrm{N}_{2}$ adsorption at $77 \mathrm{~K}$ (Autosorb I, Nova 2000, Quantahrome Instruments); isothermal data was analysed to determine surface area [22], mesopore characteristics [23, 24], and average pore width and pore size distribution [25]. Point of zero charge $\left(\mathrm{pH}_{\mathrm{PZC}}\right)$ was determined by adding $100 \mathrm{mg}$ of the sorbent to each of a series of flasks containing $100 \mathrm{~cm}^{3}$ of $0.01 \mathrm{~N} \mathrm{NaCl}$, in which the initial $\mathrm{pH}$ was adjusted (pH 2 to 12), using $0.01 \mathrm{~N} \mathrm{HCl}$ or $0.01 \mathrm{~N} \mathrm{NaOH}$. Initial $\mathrm{pH}$ and $\mathrm{pH}$ after $48 \mathrm{hr}$ contact were recorded and plotted; the intersection denoting $\mathrm{pH}_{\mathrm{PZC}}$.

\section{Error Analysis}

Appropriateness of the series of kinetic and isotherm models applied to the experimental data acquired in this work was determined using the absolute relative error (ARE) and coefficient of determination $\left(\mathrm{R}^{2}\right.$ ) (Eqs. 4 and 5) [26, 27], using the criteria of ARE close to 0 and $R^{2}$ close to 1 .

$$
\begin{aligned}
& R^{2}=1-\frac{\sum_{\mathrm{i}=1}^{\mathrm{n}}\left(q_{\mathrm{e}, \text { exp }}-q_{\mathrm{e}, \mathrm{cal}}\right)^{2}}{\sum_{\mathrm{i}=1}^{\mathrm{n}}\left(q_{\mathrm{e}, \exp }\right)^{2}-\left[\sum_{\mathrm{i}=1}^{\mathrm{n}}\left(q_{\mathrm{e}, \text { exp }}\right)^{2} / \mathrm{n}\right]} \\
& \mathrm{ARE}=\frac{1}{\mathrm{n}} \sum_{\mathrm{i}=1}^{\mathrm{n}}\left|\frac{\left(q_{\mathrm{e}, \exp }-q_{\mathrm{e}, \mathrm{cal}}\right)}{q_{\mathrm{e}, \exp }}\right|
\end{aligned}
$$

where $\mathrm{n}, \mathrm{q}_{\mathrm{exp}}$, and $\mathrm{q}_{\mathrm{cal}}$ are the range of input data, experimental, and calculated uptake of $\mathrm{Cd}(\mathrm{II})$ ions, respectively.

\section{Results and Discussion}

\section{Sorbent Characterisation}

The FTIR spectra obtained for native camelthorn (Fig. 1a), exhibited an absorption band at $3323 \mathrm{~cm}^{-1}$, due to the stretching vibration of hydrogen-bonded alcoholic and phenolic -OH groups; a weak band at $2915 \mathrm{~cm}^{-1}$, which is most probably due to $\mathrm{C}-\mathrm{H}$ bond stretching vibrations [28]; a peak at $1625 \mathrm{~cm}^{-1}$, ascribed to $\mathrm{C}=\mathrm{C}$ stretching [29]; weak bands between 1400 and $1500 \mathrm{~cm}^{-1}$ indicating aromatic ring C-C bonds; a relatively wide band at $1000 \mathrm{~cm}^{-1}$, related to the presence of C-O groups [30]. From Fig. 1b, the additional absorption peaks for MATC are observed at $1729 \mathrm{~cm}^{-1}$, assigned to stretching vibrations of the newly formed ester carbonyl groups resulting from modification of camelthorn with malonic acid; and the characteristic peak at $1443 \mathrm{~cm}^{-1}$ for the absorption of $-\mathrm{OH}$ bending vibrations in - $\mathrm{COOH}$. This evidence indicates the successful modification of camelthorn with malonic acid [31] to create new ester moieties on the surface. Figure 1c shows the FT-IR spectra of MATC loaded with Cd(II) ions, as obtained postadsorption. In comparison with the native camelthorn and MATC sorbents (Fig. 1a, b), the intensities of $-\mathrm{OH}, \mathrm{C}=\mathrm{O}$, and $\mathrm{C}-\mathrm{O}$ groups are increased, which indicates their significant role in the adsorption of $\mathrm{Cd}(\mathrm{II})$ ions onto the surface of MATC, and Cd(II) adsorption onto MATC may involve a complexation mechanism. It should be noted that while the FTIR results provide an indication of the groups involved in attracting $\mathrm{Cd}$ (II) ions to the sorbent surface, they do not provide any quantitative analysis or information about the level of affinity of the metal to the functional groups present within the sorbents.

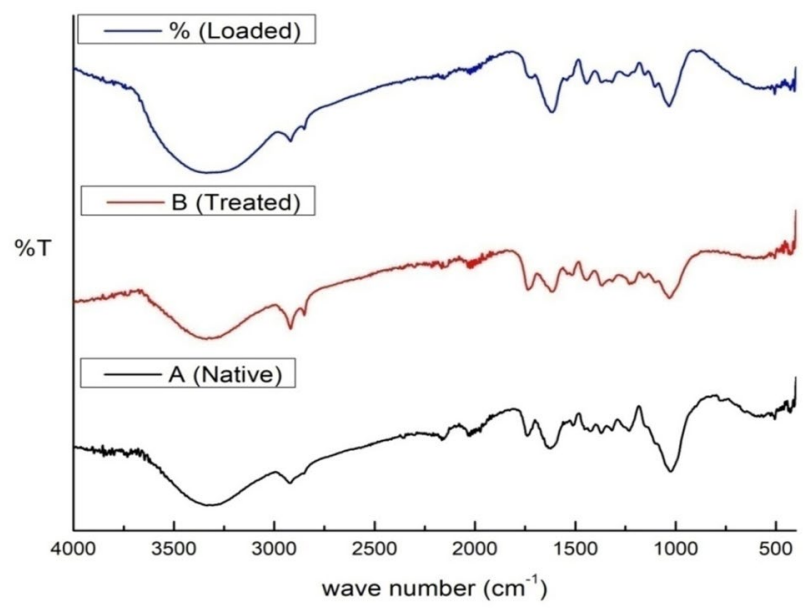

Fig. 1 FT-IR of (a) camelthorn biomass, (b) malonic acid treated camelthorn (MATC), (c) MATC loaded with Cd(II) ions 
Figure 2a shows the surface morphology of MATC, and this image reveals a cluttered and agglomerated material with pores present. After metal adsorption, the pores present on the MATC surface were occupied with Cd(II) ions, resulting in the formation of a non-uniform and rough surface. The Cd(II) deposited in the surface pores is in the form of aggregates, thus multi layers of $\mathrm{Cd}$ metal cover the modified camelthorn surface (Fig. 2b). This morphological change confirms the presence of $\mathrm{Cd}$ metal on the sorbent surface post-adsorption. Additional confirmation is provided

(a)

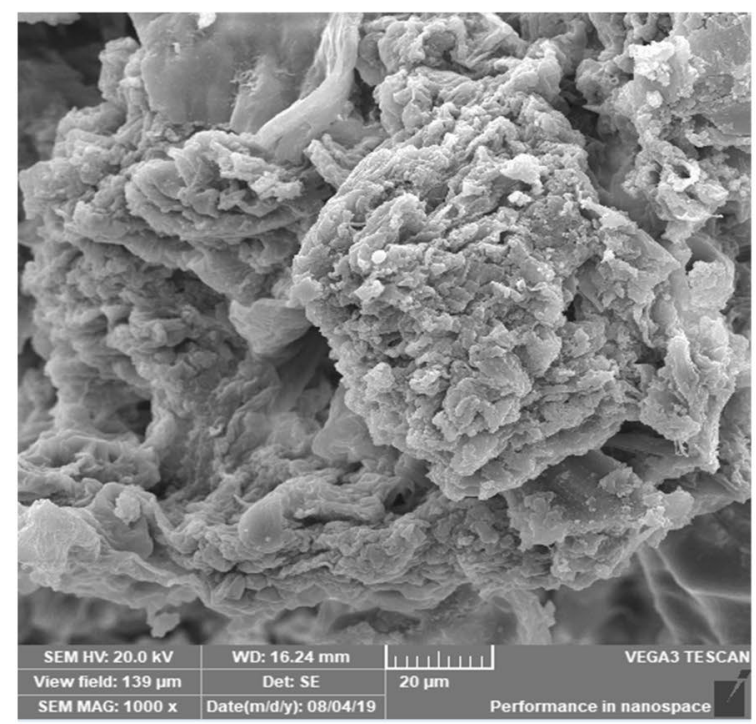

by the EDX spectra of MATC loaded with Cd(II) ions, presented within the chart of Fig. 2c, with the sharp peaks corresponding to the presence of elemental cadmium.

Figure $3 \mathrm{a}$ presents the nitrogen adsorption-desorption isotherms obtained for MATC at $-196{ }^{\circ} \mathrm{C}$, while the pore size distribution is shown in Figure $3 \mathrm{~b}$. The sorbent showed a BET surface area of $1.3 \mathrm{~m}^{2} \mathrm{~g}^{-1}$ and a pore volume of 2 $\times 10^{-3} \mathrm{~cm}^{3} \mathrm{~g}^{-1}$. A hysteresis loop can be observed in the adsorption-desorption profiles, which, according to the IUPAC classification, is associated with a Type IV isotherm,

\section{(c)}

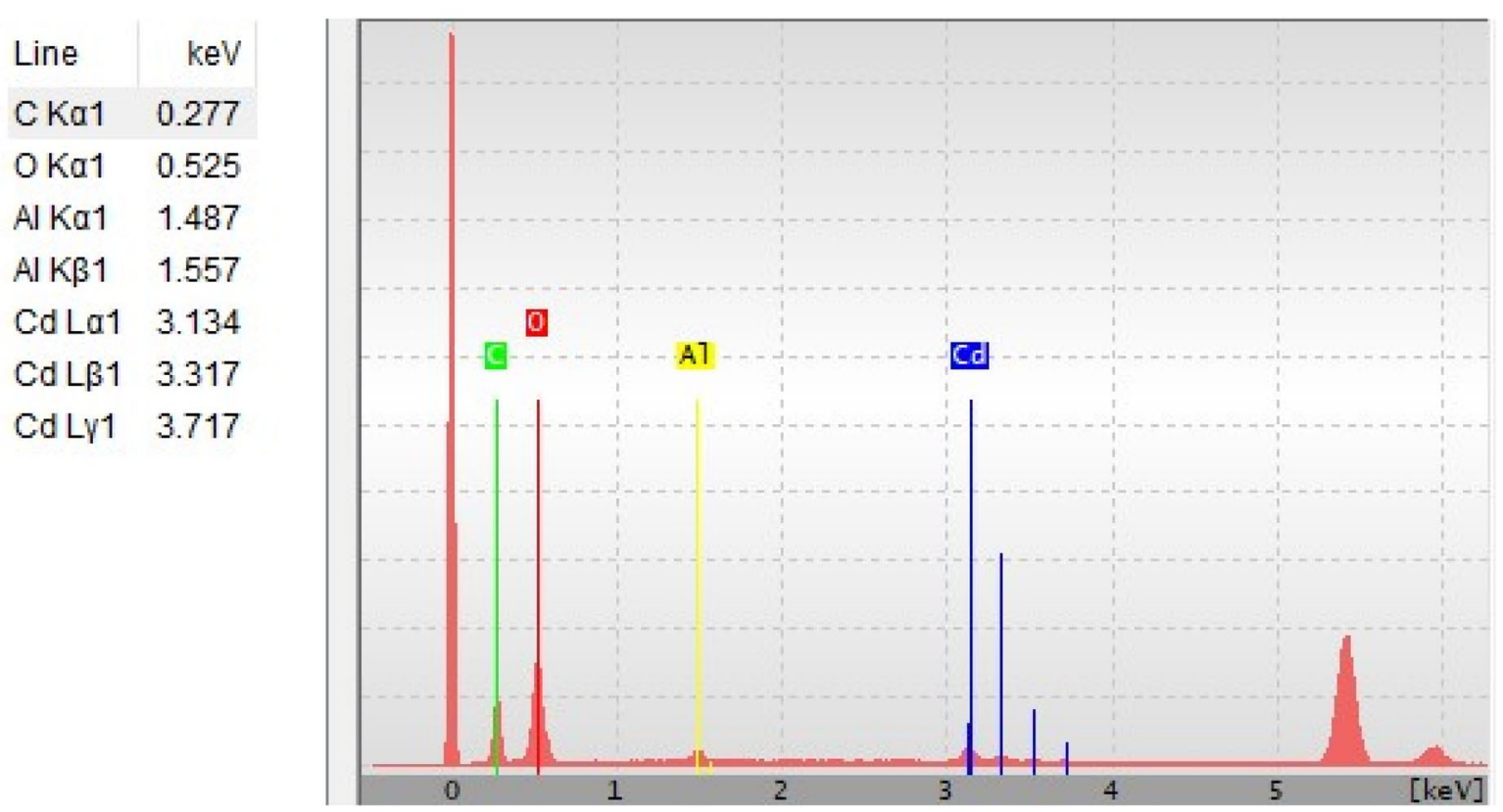

Fig. 2 SEM of (a) malonic acid treated camelthorn (MATC), (b) MATC-loaded with Cd(II)ions, and (c) EDX of MATCloaded with Cd(II)ions 
(a)

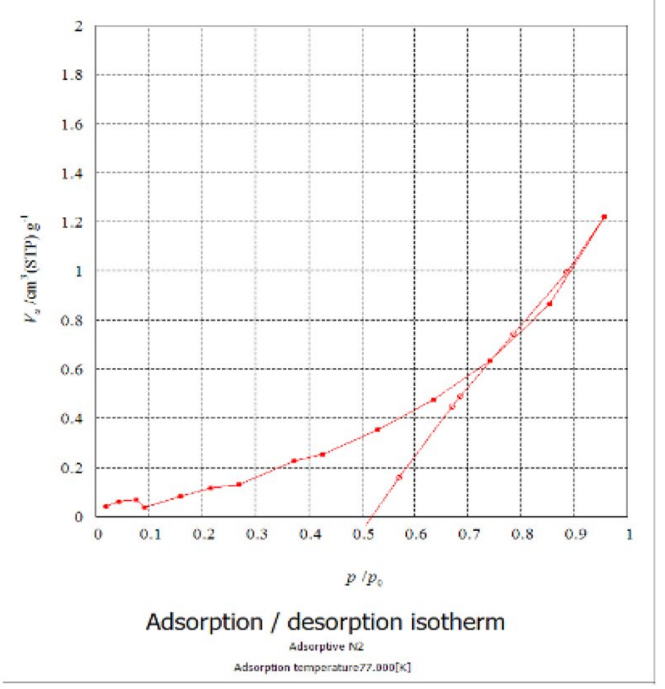

(b)

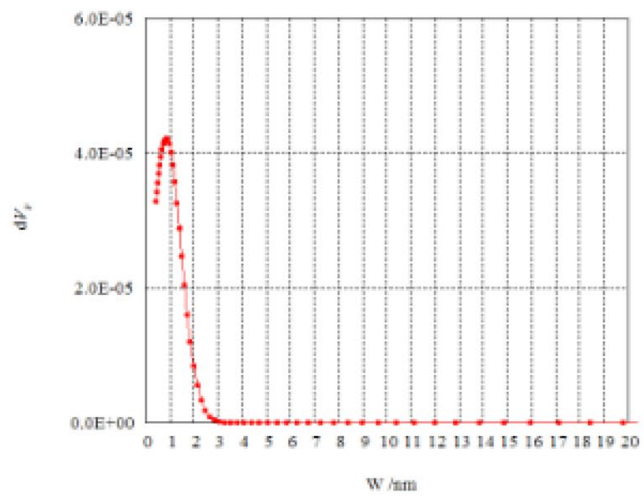

NLDFT/GCMC Pore size distribution analysis chaptan bran

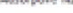

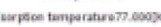

Fig. 3 (a) Nitrogen adsorption-desorption isotherms and (b) pore size distribution for malonic acid treated camelthorn

suggesting mesoporous character [32]. This observation is supported by the distribution shown in Figure $3 \mathrm{~b}$, which indicates that the average pore size is $\sim 6 \mathrm{~nm}$ and that most of the surface pores fall within the mesoporous structure range $(2-50 \mathrm{~nm})$, which are capable of admitting not only metal ions, but also large sized dye molecules [33].

\section{Factors Affecting Modification of Camelthorn Biomass}

\section{Effect of Malonic Acid Concentration}

Figure 4 shows the extent of modification of camelthorn biomass, expressed as meq-COOH/100g sorbent, as a function of malonic acid concentration. The carboxylic acid content increases markedly, from 70 to $258.8 \mathrm{meq} / 100 \mathrm{~g}$ sorbent, with increasing malonic acid concentration (2.4 to 14.4 mmol L ${ }^{-1}$ ); further increases in malonic acid concentration resulted in a plateau at a maximum level of functionalisation. The increase in carboxylic acid content may be attributed to the greater availability of malonic acid molecules within the proximity of the camelthorn cellulose macromolecules with increasing malonic acid concentration, which is converted to the corresponding anhydride through dehydration under the effect of heat (Scheme 1). The anhydride obtained reacts with the cellulose hydroxyl groups of camelthorn to produce the MATC sorbent. Functionalisation happens at the immobile hydroxyl moieties of the sorbent surface, hence, increased malonic acid availability is essential for increased reaction and conversion of these surface groups.

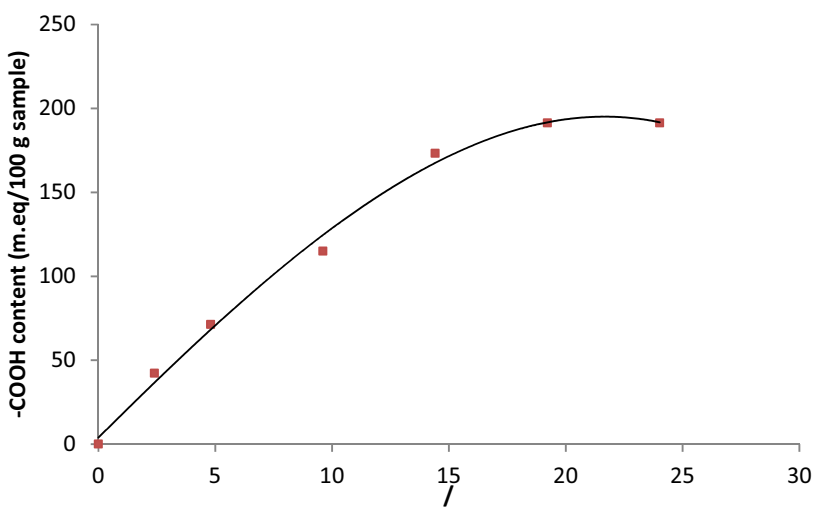

Fig. 4 Effect of malonic acid concentration on extent of modification expressed as meq-COOH/100 g sample of malonic acid treated camelthorn. Reaction conditions: mass of camelthorn biomass: $2 \mathrm{~g}$; particle size range: $50-125 \mu \mathrm{m}$; dehydration temperature: $140{ }^{\circ} \mathrm{C}$; reaction time: $2 \mathrm{~h}$

\section{Effect of Dehydration Temperature}

Figure 5 shows the effect of dehydration temperature on carboxylic acid content of MATC, which increases from 120.8 to $258.8 \mathrm{meq} / 100 \mathrm{~g}$ sorbent $\left(100\right.$ to $\left.140^{\circ} \mathrm{C}\right)$ before a decrease at higher temperatures $\left(>140{ }^{\circ} \mathrm{C}\right)$. At temperatures in the range $100-140{ }^{\circ} \mathrm{C}$, malonic acid converts of the anhydride analogue (Scheme 1), and reaction kinetics will be increased with thermal stimulation; above this temperature, catalytic effects (decarboxylation) may impede reaction, and cellulosic material may be reduced to ash at very high temperatures $\left(>150^{\circ} \mathrm{C}\right)$. 




Fig. 5 Effect of dehydration temperature on extent of modification expressed as meq - $\mathrm{COOH} / 100 \mathrm{~g}$ sample of malonic acid treated camelthorn. Reaction conditions: mass of camelthorn biomass: $2 \mathrm{~g}$; particle size range: $50-125 \mu \mathrm{m}$; reaction time: $2 \mathrm{~h}$; malonic acid concentration: $14.4 \mathrm{mmol} \mathrm{L}^{-1}$

\section{Effect of Reaction Time}

Figure 6 shows the influence of reaction time on carboxylic acid content of MATC, at $140{ }^{\circ} \mathrm{C}$ and reaction times in the range $30-180 \mathrm{~min}$. Figure 6 shows an increase from 150 to $258 \mathrm{meq} / 100 \mathrm{~g}$ sorbent for short to medium increasing reaction times, before a subsequent decrease at longer reaction times. These longer reaction intervals may be attributed to catalytic effects leading to the formation of carboxylic acid moieties at increased exposure times.

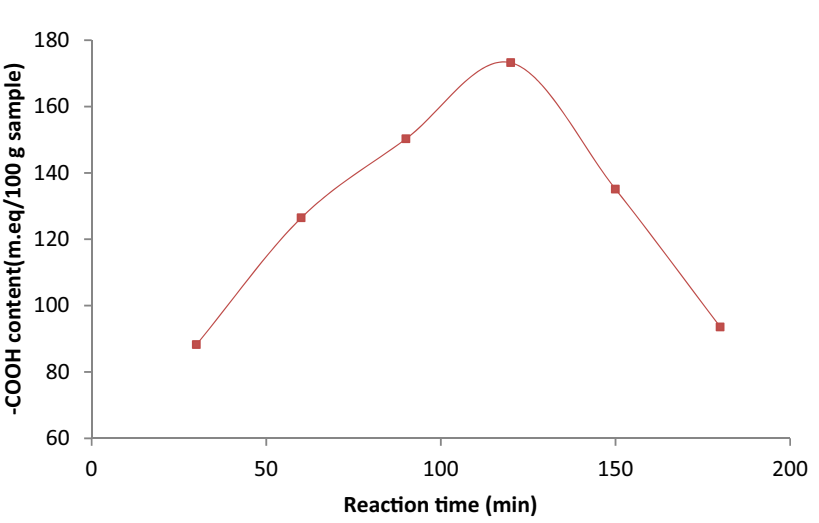

Fig. 6 Effect of reaction time on extent of modification expressed as meq-COOH/100 g sample of malonic acid treated camelthorn. Reaction conditions: mass of camelthorn biomass: $2 \mathrm{~g}$; particle size range: 50-125 $\mu \mathrm{m}$; malonic acid concentration: $14.4 \mathrm{mmol} \mathrm{L}^{-1}$; dehydration temperature: $140{ }^{\circ} \mathrm{C}$

\section{Factors Affecting Adsorption}

\section{Effect of Solution pH}

Figure 7a shows the point of zero charge $\left(\mathrm{pH}_{\mathrm{PZC}}\right)$ data for the surface of the MATC sorbent, allowing the $\mathrm{pH}$ at which the surface of MATC has neutral charge to be determined. At a solution $\mathrm{pH}$ higher than $\mathrm{pH}_{\mathrm{PZC}}$, the surface will be mainly negatively charged, and mainly positively charged if a solution $\mathrm{pH}$ is lower than $\mathrm{pH}_{\mathrm{PZC}}[19,34]$, hence, the $\mathrm{pH}_{\mathrm{PZC}}$ gives information about the electrostatic interaction between the adsorbate and the sorbent surface [35]. The $\mathrm{pH}_{\mathrm{PZC}}$ of MATC was determined as 4.0, indicating that it is acidic in nature; when the $\mathrm{pH}$ value of the solution is higher than $\mathrm{pH}_{\mathrm{PZC}}$, the charge of the MATC surface will be negative and favours the binding of cations, and when the $\mathrm{pH}$ value of the solution is lower than the $\mathrm{pH}_{\mathrm{PZC}}$, the surface charge of the sorbent will be positive and, therefore, the adsorption of cations is unlikely [36].

(a)

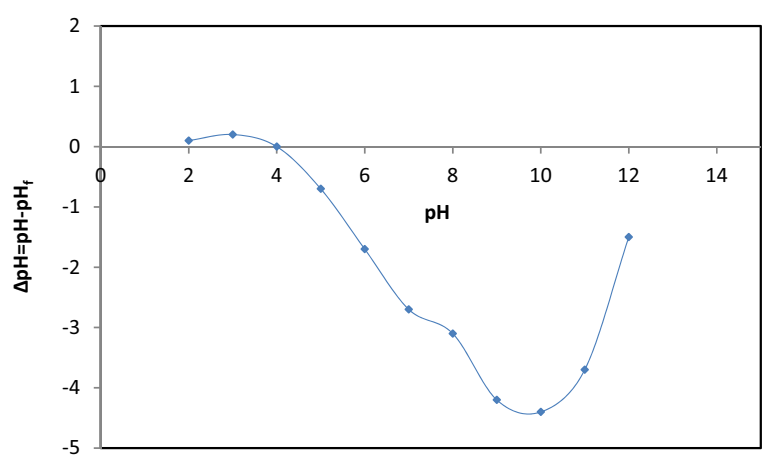

(b)

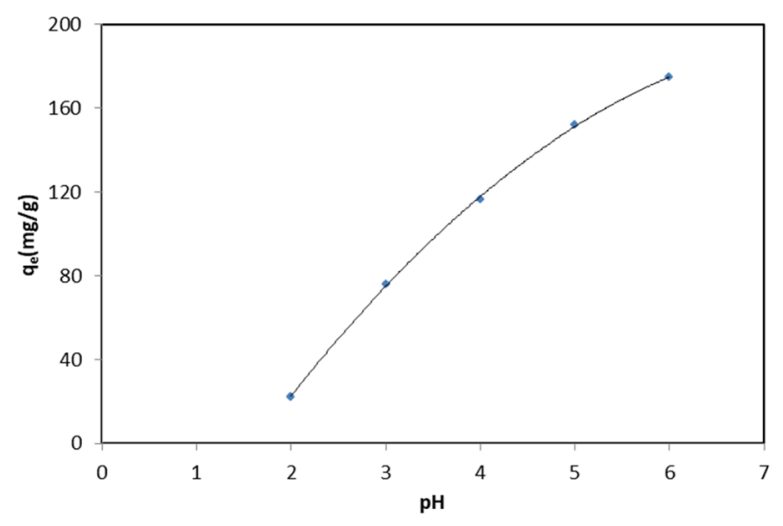

Fig. 7 (a) $\mathrm{pH}_{\mathrm{ZPC}}$ of malonic acid treated camelthorn at room temperature; (b) Influence of $\mathrm{pH}$ on adsorption capacity of $\mathrm{Cd}(\mathrm{II})$ ions onto MATCat $30{ }^{\circ} \mathrm{C}$. Reaction conditions: adsorbent dose: $0.3 \mathrm{~g} \mathrm{~L}^{-1}$; $\mathrm{Cd}(\mathrm{II})$ ion concentration: $300 \mathrm{mg} \mathrm{L}^{-1}$; contact time: $2 \mathrm{~h}$; adsorption temperature, $30{ }^{\circ} \mathrm{C}$; particle size range, $50-125 \mu \mathrm{m}$; carboxyl content, $258.5 \mathrm{meq} / 100 \mathrm{~g}$ sample 
$\mathrm{Cd}(\mathrm{II})$ ions are known to precipitate from solution at $\mathrm{pH}$ values greater than 7, thus, the $\mathrm{pH}$ was kept below 7 in all experiments within his study. The relationship between $\mathrm{pH}$ and adsorption capacity of $\mathrm{Cd}(\mathrm{II})$ ions onto MATC is presented in Figure $7 \mathrm{~b}$, as a function of increasing $\mathrm{pH}$. As $\mathrm{pH}$ increases from 2 to 6 , there is an increase in $\mathrm{Cd}(\mathrm{II})$ uptake from 22 to a maximum value of $175 \mathrm{mg} \mathrm{g}^{-1}$ for this system. At lower $\mathrm{pH}$, more hydrogen ions (protons) are available within the solution, leading to strong competition with metal ions towards the active sites of the sorbent $[14,37]$; at such levels there will also be electrostatic repulsion between the more charged surface of the sorbent and the charged $\mathrm{Cd}(\mathrm{II})$ ions. At higher $\mathrm{pH}$, the influences of competition and electrostatic repulsion are reduced, and adsorption is enhanced, as observed here. Such behaviour has been observed previously for $\mathrm{Cd}(\mathrm{II})$ adsorption on pine sawdust [19]. Another possible reason for increasing adsorption capacity with increasing $\mathrm{pH}$ from 3-6 can be attributed to the following reactions:

$2 \mathrm{Camelthorn}-\mathrm{COOH} \Leftrightarrow 2 \mathrm{Camelthorn}-\mathrm{COO}^{-}+2 \mathrm{H}^{+}$

2Camelthorn $-\mathrm{COO}^{-}+\mathrm{Cd}^{2+} \Leftrightarrow(\text { Camelthorn }-\mathrm{COO})_{2} \cdot \mathrm{Cd}$

Equation 6 represents deprotonation, the first stage in ion exchange, while Eq. 7 represents the adsorption of $\mathrm{Cd}(\mathrm{II})$ ions onto the deprotonated MATC. The $\mathrm{pH}_{\mathrm{pzc}}$ of TMCC was determined as 4.0, which denotes the point at which a neutral charge is obtained and indicating an acidic nature for the surface of the TMCC adsorbent. The optimum pH for MATC to adsorb Cd(II) is 6.0 (Figure 7a) which is higher than the $\mathrm{pH}_{\mathrm{PZC}}$. This leads to a predominantly negative sorbent surface, which may lead to electrostatic attraction (ion exchange) between the $\mathrm{Cd}(\mathrm{II})$ ions and negatively charged surface [38].

\section{Effect of Sorbent Dose}

The effect of sorbent dose on adsorption capacity and percentage removal of $\mathrm{Cd}(\mathrm{II})$ ions onto MATC were studied at $\mathrm{pH} 6$ (sorbent concentrations: $1-10 \mathrm{~g} \mathrm{~L}^{-1}$, initial metal ion concentration: $300 \mathrm{mg} \mathrm{L}^{-1}$ ). It is clear from Fig. 8 that the removal of $\mathrm{Cd}(\mathrm{II})$ ions increased from 15 to $98 \%$ with increasing sorbent concentration $\left(0.3\right.$ to $\left.10 \mathrm{~g} \mathrm{~L}^{-1}\right)$, which may be due to the availability of more adsorption sites [39]. In contrast, uptake $\left(\mathrm{q}_{\mathrm{e}}\right)$ decreased with increasing sorbent dosage, which may be due to overcrowding of sorbent particles in solution and competition between metal ions for active sites.

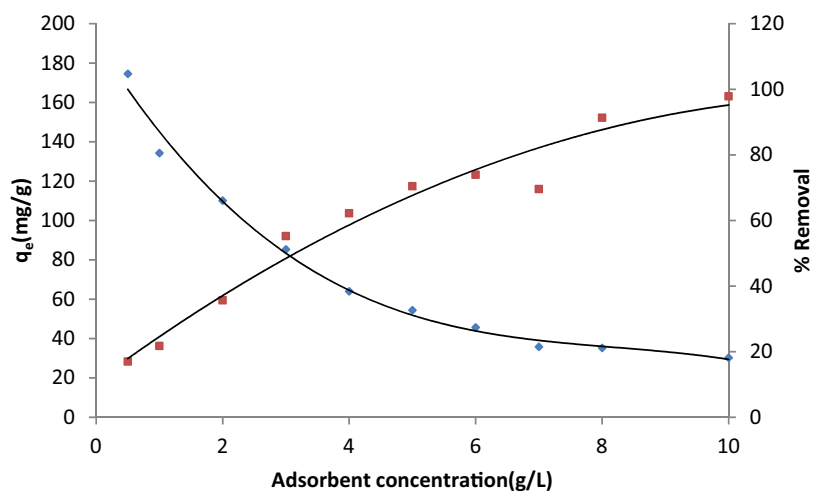

Fig. 8 Effect of sorbent dose on both adsorption capacity () and percentage removal () of $\mathrm{Cd}$ (II) ions malonic acid treated camelthorn at $30{ }^{\circ} \mathrm{C}$. Reaction conditions: $\mathrm{Cd}(\mathrm{II})$ ion concentration: $300 \mathrm{mg} \mathrm{L}^{-1}$; $\mathrm{pH}$ 6; contact time: $2 \mathrm{~h}$; adsorption temperature: $30{ }^{\circ} \mathrm{C}$; particle size range: $50-125 \mu \mathrm{m}$; carboxyl content: $258.5 \mathrm{meq} / 100 \mathrm{~g}$ sample

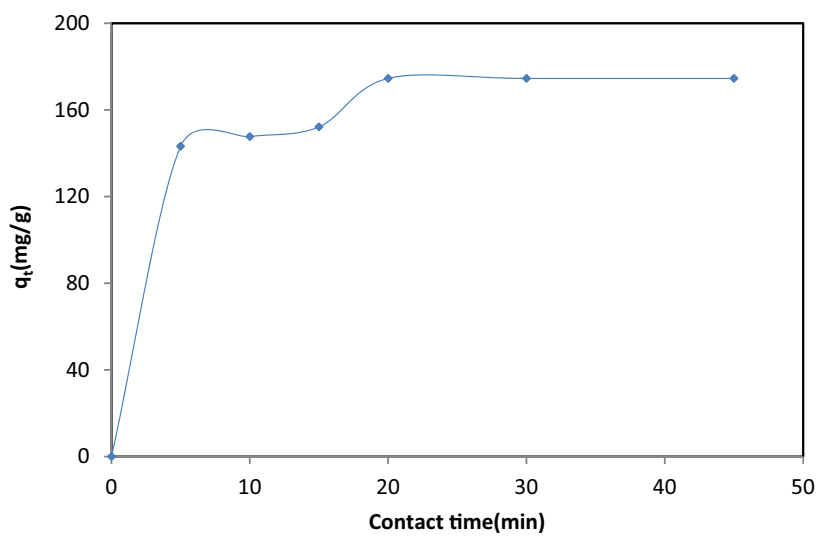

Fig. 9 Influence of contact time on adsorption capacity of Cd(II) ions onto malonic acid treated camelthorn at $30{ }^{\circ} \mathrm{C}$. Reaction conditions: adsorbent dose: $0.3 \mathrm{~g} \mathrm{~L}^{-1}$; Cd(II) ion concentration: $300 \mathrm{mg} \mathrm{L}^{-1} ; \mathrm{pH}$ 6; adsorption temperature: $30{ }^{\circ} \mathrm{C}$; particle size range: $50-125 \mu \mathrm{m}$; carboxyl content: $258.5 \mathrm{meq} / 100 \mathrm{~g}$ sample

\section{Influence of Time}

The influence of exposure time on adsorption capacity of $\mathrm{Cd}(\mathrm{II})$ ions onto MATC at a Cd concentration of 300 $\mathrm{mg} \mathrm{L}^{-1}$ is shown in Fig. 9, with adsorption increasing rapidly to $145 \mathrm{mg} \mathrm{g}^{-1}$ at $5 \mathrm{~min}$, with only a small increase between 5 and $20 \mathrm{~min}$. Beyond $20 \mathrm{~min}$, adsorption remains constant indicating that the equilibrium state has been achieved. The highest uptake of Cd(II) ions onto MATC was $175 \mathrm{mg} \mathrm{g}^{-1}$. The initial, rapid adsorption of $\mathrm{Cd}$ (II) ions could be due to the presence of active surface sites on the sorbent; after which such sites are occupied, which reduces $\mathrm{Cd}(\mathrm{II})$ adsorption [30]. The reported saturation at $20 \mathrm{~min}$ for $\mathrm{Cd}(\mathrm{II})$ adsorption onto MATC is quicker than the 60 min timeframe, previously reported for $\mathrm{Cd}(\mathrm{II})$ ion adsorption on modified sawdust [19]. 


\section{Influence of Adsorbate Concentration Under Isothermal Conditions}

Isotherm models relate adsorption uptake, $\mathrm{q}_{\mathrm{e}}$ (metal adsorption per unit weight of sorbent), to the equilibrium adsorbate concentration within the bulk fluid phase, $\mathrm{C}_{\mathrm{e}}$, and several models, with either two or three parameters, have been reported to describe experimental data of adsorption isotherms. In this study, eight such models were selected to describe the adsorption equilibrium of Cd(II) onto MATC.

The Langmuir model [40] is generally utilised for pollutant adsorption from solution and is founded on the key assumptions that adsorption is limited to monolayer formation, adsorption only occurs at surface sites in the energetically homogeneous sorbent surface, and molecules adsorbed on neighbouring sites do not interact. The model is represented by:

$q_{\mathrm{e}}=\frac{\mathrm{K}_{\mathrm{L}} \cdot \mathrm{C}_{\mathrm{e}}}{1+\mathrm{a}_{\mathrm{L}} \cdot \mathrm{C}_{\mathrm{e}}}$

$\mathrm{K}_{\mathrm{L}}\left(\mathrm{L} \mathrm{g}^{-1}\right)$ and $\mathrm{a}_{\mathrm{L}}\left(\mathrm{L} \mathrm{mg}^{-1}\right)$ are isotherm model constants, and $\mathrm{k}_{\mathrm{L} /} \mathrm{a}_{\mathrm{L}}$ is the maximum capacity $\left(\mathrm{q}_{\max }\right) \cdot \mathrm{C}_{\mathrm{e}}$ is the equilibrium adsorbate concentration, measured in $\mathrm{m} \mathrm{L}^{-1}$, and $\mathrm{q}_{\mathrm{e}}$ is normalised uptake of $\mathrm{Cd}(\mathrm{II})$ ions $\left(\mathrm{mg} \mathrm{g}^{-1}\right)$.

The Freundlich model was developed for multilayer systems with a logarithmic distribution of surface site energies across the heterogeneous surface. This model is based on the fact that the higher affinity sites are occupied initially and that total uptake is summed for all sites. The model also assumes multilayer adsorption on the surface and predicts infinite adsorption uptake. The model is expressed by [41]:

$\mathrm{q}_{\mathrm{e}}=\mathrm{K}_{\mathrm{F}} \cdot \mathrm{C}_{\mathrm{e}}^{1 / \mathrm{n}}$

$\mathrm{q}_{\mathrm{e}}$ and $\mathrm{C}_{\mathrm{e}}$ are as previously defined, $\mathrm{K}_{\mathrm{F}}$ and $\mathrm{n}$ are Freundlich constants related to uptake capacity and likelihood, respectively.

The Redlich-Peterson model [42], featuring aspects from Freundlich and Langmuir isotherms, favours multilayer formation. An empirically derived model, it exhibits Henry's behaviour at dilute concentrations and reduces to the Freundlich model at high ionic strengths. The model is represented by:

$\mathrm{q}_{\mathrm{e}}=\frac{\mathrm{k}_{\mathrm{R}} \cdot \mathrm{C}_{\mathrm{e}}}{1+\alpha_{\mathrm{R}} \cdot \mathrm{C}_{\mathrm{e}}^{\mathrm{g}}}$

$\mathrm{q}_{\mathrm{e}}$ and $\mathrm{C}_{\mathrm{e}}$ are as previously defined, $\mathrm{k}_{\mathrm{R}}\left(\mathrm{L} \mathrm{g}^{-1}\right)$ and $\alpha_{\mathrm{R}}$ are the constants of adsorption, the exponential term $\mathrm{g}(0$ to 1), means that Equation 10 reduces to the Langmuir model at unity, and, as $\mathrm{g}$ tends to 0 , Eq. 10 reduces to Henry's law, and Henry's constant is given by $k_{R} /\left(1+\alpha_{R}\right)$.
Heterogeneous adsorption systems can also be described by the Toth model [43]; which is again a modified form of the Langmuir equation, satisfying both dilute and concentrated boundaries. The model is expressed by:

$q_{\mathrm{e}}=\frac{\mathrm{K}_{\mathrm{T}} \cdot \mathrm{C}_{\mathrm{e}}}{\left(\mathrm{a}_{\mathrm{T}}+\mathrm{C}_{\mathrm{e}}\right)^{1 / \mathrm{t}}}$

$\mathrm{q}_{\mathrm{e}}$ and $\mathrm{C}_{\mathrm{e}}$ are as previously defined, $\mathrm{k}_{\mathrm{T}}$ is the Toth isotherm constant, $\mathrm{a}_{\mathrm{T}}$ is the maximum uptake, and $\mathrm{t}$, in the term $1 / \mathrm{t}$, indicates the level of heterogeneity within the sorbent, where unity results in the model reducing the Langmuir model, i.e. a homogeneous system.

Another combinatorial model, the Sips model [44] is founded on the presence of a heterogeneous surface; the model is expressed by:

$q_{\mathrm{e}}=\frac{\mathrm{k}_{\mathrm{s}} \cdot C_{\mathrm{e}}^{\beta_{\mathrm{s}}}}{1+a_{s} \cdot C_{\mathrm{e}}^{\beta_{\mathrm{s}}}}$

$\mathrm{q}_{\mathrm{e}}$ and $\mathrm{C}_{\mathrm{e}}$ are as previously defined, $\mathrm{k}_{\mathrm{s}}\left(\mathrm{L} \mathrm{g}^{-1}\right)$ and $\mathrm{a}_{\mathrm{s}}$ $\left(\mathrm{L} \mathrm{mg}^{-1}\right)$ are the Sips isotherm constants, and $\beta_{\mathrm{S}}$ is an exponent. The Sips isotherm reduces to the Freundlich model for dilute systems, while predicting completion of a single adsorption layer, as expected from the Langmuir model, for concentrated systems.

The Hill model [45] is founded on cooperative processes and assumes a homogeneous surface is present, the model is described by:

$q_{\mathrm{e}}=\frac{q_{\mathrm{s}_{\mathrm{H}}} \cdot C_{\mathrm{e}}^{\mathrm{n}_{\mathrm{H}}}}{K_{\mathrm{D}} \cdot C_{\mathrm{e}}^{\mathrm{n}_{\mathrm{H}}}}$

$\mathrm{q}_{\mathrm{e}}$ and $\mathrm{C}_{\mathrm{e}}$ are as previously defined, $\mathrm{k}_{\mathrm{D}}$ is the Hill constant $(\mathrm{mg}), \mathrm{n}_{\mathrm{H}}$ is the Hill cooperativity coefficient, and $\mathrm{q}_{\mathrm{SH}}$ indicates maximum uptake $\left(\mathrm{mg} \mathrm{mg}^{-1}\right)$.

Khan [46] proposed a common model for adsorption from dilute dual adsorptive systems using pure system data, however, the model can also be applied in this case. The general Khan isotherm model for a single solute is represented by:

$q_{\mathrm{e}}=\frac{\mathrm{q}_{\max } \mathrm{b}_{\mathrm{k}} \mathrm{C}_{\mathrm{e}}}{\left(1+\mathrm{b}_{\mathrm{k}} \mathrm{C}_{\mathrm{e}}\right)^{\mathrm{a}_{\mathrm{k}}}}$

$\mathrm{q}_{\mathrm{e}}$ and $\mathrm{C}_{\mathrm{e}}$ are as previously defined, $\mathrm{a}_{\mathrm{K}}$ is an exponent and $\mathrm{b}_{\mathrm{K}}$ is the Khan isotherm constant.

Jossens [47], again proposed a model based on a distribution of energies across the sorbent surface, i.e. a heterogeneous surface, controlling adsorbate-adsorbent binding. The model is represented by:

$q_{\mathrm{e}}=\frac{\mathrm{K}_{\mathrm{J}} \mathrm{C}_{\mathrm{e}}}{\left(1+\mathrm{JC}_{\mathrm{e}}^{\beta}\right)}$ 
Table 1 Isotherm constants of two-parameter models for $\mathrm{Cd}(\mathrm{II})$ ion adsorption onto malonic acid treated camelthorn biomass at $30^{\circ} \mathrm{C}$

\begin{tabular}{lllll}
\hline Isotherm Model & Parameter & Value & Error Analysis & Value \\
\hline Langmuir & $\mathrm{a}_{\mathrm{L}}$ & $\begin{array}{c}0.0035 \\
\mathrm{~L} \mathrm{mg}^{-1}\end{array}$ & $\mathrm{R}^{2}$ & 0.9998 \\
& & $\begin{array}{c}1000 \mathrm{mg} \mathrm{g}^{-1} \\
\text { Freundlich }\end{array}$ & $\mathrm{ARE}$ & 0.1238 \\
& $\mathrm{q}_{\max }$ & $2.035 \mathrm{~L} \mathrm{~g}^{-1}$ & & \\
& $\mathrm{~N}$ & 2.333 & $\mathrm{R}^{2}$ & 0.9961 \\
& $\mathrm{~K}_{\mathrm{F}}$ & 24.935 & $\mathrm{ARE}$ & 0.6737 \\
& & $\mathrm{mg} \mathrm{g}^{-1}$ & & \\
\hline
\end{tabular}

Table 2 Isotherm constants of three-parameter isotherm models used to fit data for $\mathrm{Cd}$ (II) ion adsorption onto malonic acid treated camelthorn biomass at $30{ }^{\circ} \mathrm{C}$

\begin{tabular}{llcll}
\hline Isotherm Model & Parameter & Value & Error analysis & Value \\
\hline Redlich-Peterson & $\mathrm{kg}$ & -0.0110 & $\mathrm{R}^{2}$ & 0.9965 \\
& $\alpha_{\mathrm{R}}$ & 24.60 & ARE & 0.6712 \\
Sips & $\mathrm{g}$ & 0.4335 & & \\
& $\mathrm{~K}_{\mathrm{S}}$ & 12.85 & $\mathrm{R}^{2}$ & 0.9969 \\
\multirow{5}{*}{ Toth } & $\alpha_{\mathrm{S}}$ & 0.0101 & ARE & 0.4395 \\
& $\beta_{\mathrm{S}}$ & 0.5298 & & \\
\multirow{4}{*}{ Khan } & $\mathrm{k}_{\mathrm{T}}$ & 11.81 & $\mathrm{R}^{2}$ & 0.9982 \\
& $\alpha_{\mathrm{T}}$ & 0.0800 & ARE & 0.4306 \\
\multirow{5}{*}{ Jossens } & $1 / \mathrm{t}$ & 0.4514 & & \\
& $\mathrm{q}_{\mathrm{m}}$ & 2.457 & $\mathrm{R}^{2}$ & 0.9967 \\
& $\mathrm{~b}_{\mathrm{K}}$ & 197.1 & $\mathrm{ARE}$ & 0.6568 \\
Hill & $\alpha_{\mathrm{K}}$ & 0.5670 & & \\
& $\mathrm{~K}_{\mathrm{J}}$ & 10.77 & $\mathrm{R}^{2}$ & 0.9967 \\
& $\mathrm{~J}$ & 0.3253 & ARE & 0.4940 \\
& $\mathrm{~B}$ & 0.6060 & & \\
& $\mathrm{q}_{\mathrm{SH}}$ & 500 & $\mathrm{R}^{2}$ & 0.9986 \\
& $\mathrm{n}_{\mathrm{H}}$ & 1.211 & ARE & 0.3122 \\
& $\mathrm{~K}_{\mathrm{D}}$ & 637.0 & & \\
\hline
\end{tabular}

$\mathrm{q}_{\mathrm{e}}$ and $\mathrm{C}_{\mathrm{e}}$ are as previously defined, $\mathrm{K}_{\mathrm{J}}$ is the Jossens isotherm model constant, corresponding to Henry's constant; $\mathrm{J}$ is the Jossens model constant, and $\beta$ is the Jossens model exponent, which is characteristic of the sorbent and is independent of temperature (Tables 1,2).

\section{Isotherm Modelling}

Minimisation of the errors obtained in a comparison of experimental and calculated data was performed using two error functions for all models utilised in this study. The error functions used were Average Relative Error (ARE) and the coefficient of determination $\left(\mathrm{R}^{2}\right)$, and these were optimised by non-linear regression to attenuate the function errors between the results obtained experimentally in this study and the values determined from the isotherm models applied here. The data in Table 3 also indicate that MATC has the lowest removal time compared with comparator sorbents. Figure 10 shows the experimental isotherm curves acquired in this study and the calculated curves obtained for the isotherm models applied to fit these data, namely the Langmuir and Freundlich models, which are each based on two parameters. The constants obtained for each fit for these two models, as well as the values obtained for error analyses of the fits, are shown in Table 1. It is known that $1 / \mathrm{n}$, from the Freundlich model, indicates the favourability of the adsorption process. In this study, the vale obtained was 2.333 (Table 1), which also falls within the range $0<\mathrm{n}$ $<10$, both of which suggest that adsorption of $\mathrm{Cd}(\mathrm{II})$ ions onto MATC is expected [31]. The data presented in Table 1 demonstrate that the Langmuir model provides the most appropriate description of the experimental data, suggesting that adsorption within the current system is limited to monolayer formation on a homogeneous surface, which agrees with previous results reported for $\mathrm{Cd}(\mathrm{II})$ ions adsorption on aminated hydroximoyl camelthorn [20]. Figures 10 and 11 show comparisons between the experimental and theoretical data for all models studied and parameters determined for each of the fits are presented in Tables 1 and 2. From the results obtained, it is evident that the Langmuir model gives the most appropriate fit to experimental curves, with the models ordered as Langmuir $>$ Hill $>$ Toth $>$ Sips $>$ Jossens $>$ Khan $>$ Redlich-Peterson $>$ Freundlich. The maximum uptake for $\mathrm{Cd}(\mathrm{II})$ ions onto MATC, as determined using the Langmuir model, is $582.6 \mathrm{mg} \mathrm{g}^{-1}$. Table 3 shows that the malonic acid-treated camelthorn synthesised in this
Table 3 Comparison of adsorption capacities of various sorbents for $\mathrm{Cd}(\mathrm{II})$ ions

\begin{tabular}{llcc}
\hline Adsorbent & $\begin{array}{l}\text { Adsorption capac- } \\
\text { ity }\left(\mathrm{mg} \mathrm{g}^{-1}\right)\end{array}$ & $\begin{array}{l}\text { Removal } \\
\text { time(min) }\end{array}$ & Reference \\
\hline Sulfuric acid treated cashew nut shell (STCNS) & 436.7 & 30 & {$[48]$} \\
Esterified spent grain (ESG) & 473.93 & 15 & {$[49]$} \\
Wood Apple Shell & 32.7 & 30 & {$[50]$} \\
Commercial activated carbon (CGAC) & 17.23 & 180 & {$[51]$} \\
Sawdust treated maleic acid & 180.4 & 45 & {$[19]$} \\
Malonic acid modified camelthorn & 582.6 & 20 & Present study \\
\hline
\end{tabular}




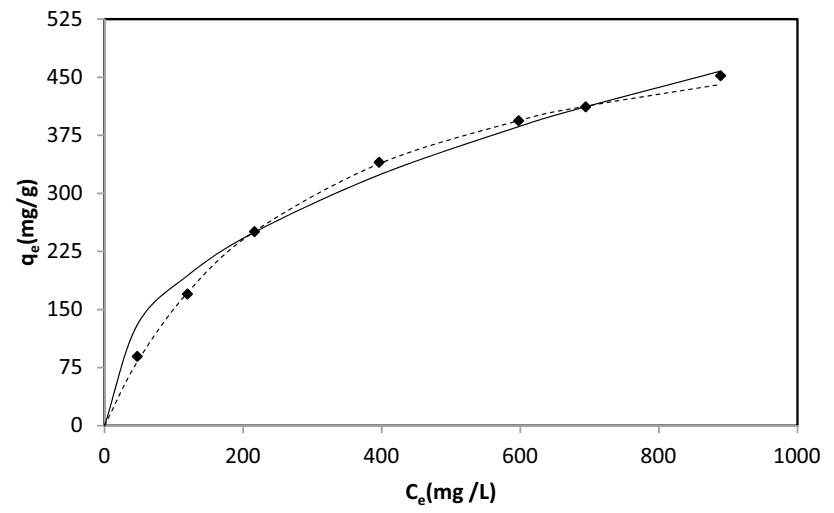

Fig. 10 Equilibrium experimental adsorption data obtained for $\mathrm{Cd}(\mathrm{II})$ ion adsorption on malonic acid treated camelthorn at $30{ }^{\circ} \mathrm{C}$, and resulting fits from Langmuir (dashed) and Freundlich (solid) and Temkin models (dotted)

(a)

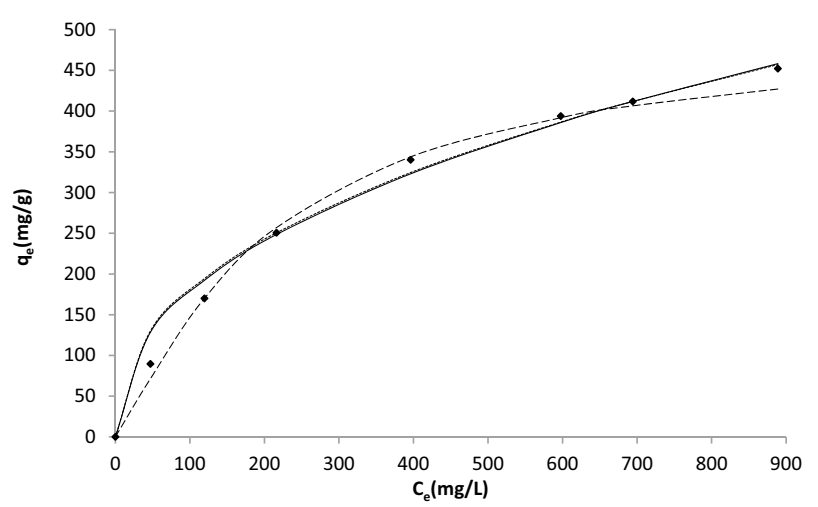

(b)

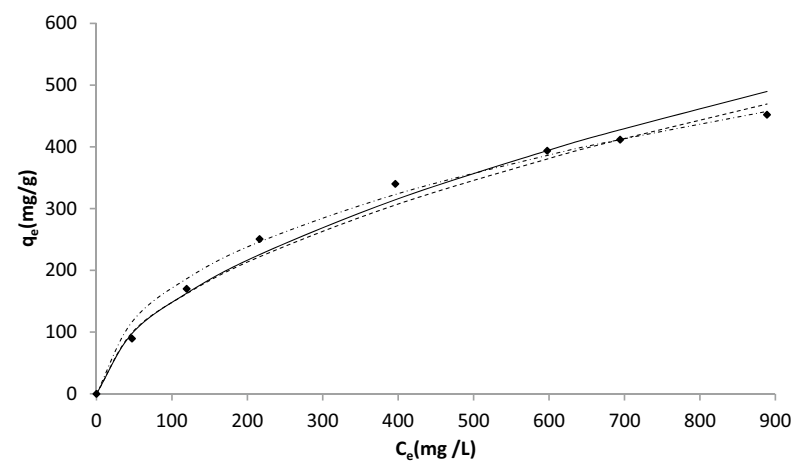

Fig. 11 Comparison between threeparameter isotherm models and equilibrium experimental adsorption data obtained for $\mathrm{Cd}(\mathrm{II})$ ion adsorption on malonic acid treated camelthornat $30{ }^{\circ} \mathrm{C}$ (). (a) Hill (long-dash), Khan (solid), Redlich-Peterson (dot); (b) Sips (dash), Toth (solid), Jossens (dash-dot)

work demonstrates enhanced adsorption capacity for $\mathrm{Cd}(\mathrm{II})$ ions from water systems in comparison with esterified spent grain $\left(473.93 \mathrm{mg} \mathrm{g}^{-1}\right)$ and a number of other sorbents [19, 48-51].

\section{Adsorption Kinetics}

It is essential that a high equilibrium adsorption capacity for a given system is obtained in tandem with appropriate kinetic parameters if these materials are to be considered as candidates for water remediation. Here, five kinetic models were used to analyse data obtained for adsorption for $\mathrm{Cd}(\mathrm{II})$ ions on MATC with respect to time. As outlined above, two error functions were utilised to evaluate the goodness of fit for each model applied to the data acquired in this study (ARE and $\mathrm{R}^{2}$ ).

The pseudo-first-order model, being founded on a physical process under diffusion control, is represented by [52]:

$q_{\mathrm{t}}=q_{\mathrm{e}}\left[1-\exp \left(-\mathrm{k}_{1} \mathrm{t}\right)\right]$

$q_{t}$ is the uptake, at time $t$ ( $\left.\mathrm{min}\right)$, of $\mathrm{Cd}$ (II) ions $\left(\mathrm{mg} \mathrm{g}^{-1}\right)$, $q_{\mathrm{e}}$ is the equilibrium uptake of $\mathrm{Cd}(\mathrm{II})$ ions $\left(\mathrm{mg} \mathrm{g}^{-1}\right), k_{1}$ is the rate constant $\left(\mathrm{min}^{-1}\right)$. Values obtained for $\mathrm{q}_{\mathrm{e}}$ and $\mathrm{k}_{1}$ are given in Table 4 with the associated error analysis.

The pseudo-second order kinetic model was derived on the basis that the adsorbate experiences physicochemical with the adsorbent, i.e. the two species share electrons; the model is represented by [53]:

$q_{\mathrm{t}}=\frac{\mathrm{k}_{2} \mathrm{q}_{\mathrm{e}}^{2} \mathrm{t}}{\left(1+\mathrm{k}_{2} \mathrm{k}_{\mathrm{e}} \mathrm{t}\right)}$

$\mathrm{t}, \mathrm{q}_{\mathrm{t}}, \mathrm{q}_{\mathrm{e}}$ are as previously defined, and $\mathrm{k}_{2}\left(\mathrm{~g} \mathrm{mg}^{-1} \mathrm{~min}^{-1}\right)$ is the rate constant. Values obtained for $\mathrm{q}_{\mathrm{e}}$ and $\mathrm{k}_{2}$ are given in Table 4 with the associated error analysis.

It is necessary, in addition to the models described above to consider the intra-particle diffusion model, to provide insight into the diffusion mechanism of the system. The model is represented by [54]:

Table 4 Kinetic model data obtained for selected models used to fit data for $\mathrm{Cd}(\mathrm{II})$ ions adsorption onto malonic acid treated camelthorn biomass at $30{ }^{\circ} \mathrm{C}$

\begin{tabular}{lllll}
\hline Isotherm Model & Parameter & Value & Error Analysis & Value \\
\hline Pseudo-first-order & $\mathrm{q}_{\mathrm{e}}$ & 174.6 & $\mathrm{R}^{2}$ & 0.9974 \\
& $\mathrm{k}_{1}$ & 0.3435 & $\mathrm{ARE}$ & 0.2852 \\
$\begin{array}{l}\text { Pseudo-second- } \\
\text { order }\end{array}$ & $\mathrm{q}_{\mathrm{e}}$ & 195.3 & $\mathrm{R}^{2}$ & 0.9985 \\
& & & & \\
Intra-particle & $\mathrm{k}_{2}$ & 0.0014 & $\mathrm{ARE}$ & 0.2209 \\
& $\mathrm{k}$ id & 7.247 & $\mathrm{R}^{2}$ & 0.9960 \\
Bangham & $\mathrm{C}$ & 125.9 & $\mathrm{ARE}$ & 0.3711 \\
& $\mathrm{q}_{\mathrm{e}}$ & 183.4 & $\mathrm{R}^{2}$ & 0.9984 \\
& $\mathrm{k}_{\mathrm{b}}$ & 0.6126 & $\mathrm{ARE}$ & 0.2452 \\
Elovich & $\mathrm{n}$ & 0.4271 & & \\
& $\alpha$ & 114844.3 & $\mathrm{R}^{2}$ & 0.9963 \\
& $\mathrm{~B}$ & 0.0744 & $\mathrm{ARE}$ & 0.3244 \\
\hline
\end{tabular}


$q_{\mathrm{t}}=\mathrm{k}_{\mathrm{id}} \mathrm{t}^{0.5}+q_{\mathrm{e}}$

$\mathrm{t}, \mathrm{q}_{\mathrm{t}}, \mathrm{q}_{\mathrm{e}}$ are as previously defined, $\mathrm{k}_{\mathrm{id}}\left(\mathrm{mg} \mathrm{g}^{-1} \min ^{1 / 2}\right)$ is the rate constant. It has previously been reported that the trend obtained graphically for $\mathrm{q}_{\mathrm{t}} \mathrm{vs}$. $\mathrm{t}^{1 / 2}$ consists of a series of steps, which each contribute to overall control of the process. An Initial curve indicates bulk diffusion, after which a linear section denotes intra-particle diffusion; the final plateau is achieved at equilibrium [55, 56]. Values obtained for $\mathrm{C}$ and $\mathrm{k}_{\mathrm{id}}$ and the associated error analysis are given in Table 4.

Pore-diffusion as rate-control can be determined using Bingham's model [57], as represented by:

$q_{\mathrm{t}}=q_{\mathrm{e}}\left[1-\exp \left(-k_{\mathrm{b}} t^{\mathrm{n}}\right)\right]$

$\mathrm{t}, \mathrm{q}_{\mathrm{t}}, \mathrm{q}_{\mathrm{e}}$ are as previously defined, and $\mathrm{k}_{\mathrm{b}}$ is the rate constant. Values obtained for $\mathrm{q}_{\mathrm{e}}, \mathrm{k}_{\mathrm{b}}$, and the associated error analysis are given in Table 4.

Finally, the Elovich model [58] is represented by:

$q_{\mathrm{t}}=\left(\frac{1}{\beta}\right) \ln (\alpha \beta t)$

$\alpha\left(\mathrm{mg} \mathrm{g}^{-1} \mathrm{~min}^{-1}\right)$ is initial rate of adsorption and $\beta$ $\left(\mathrm{g} \mathrm{mg}^{-1} \mathrm{~L}^{-1}\right)$ is made up of contributions from uptake within the system and chemisorption related activation energy. Values obtained for $\alpha$ and $\beta$ and the associated error analysis are given in Table 4.

Fits for the five kinetic models used in this study are shown in Fig. 12; the results (Table 4) show that the models can be ordered: pseudo-second-order $>$ Bangham $>$ pseudo-first-order $>$ Elovich $>$ intra-particle for goodness of fit to data acquired within this study, indicating chemical control of the process.

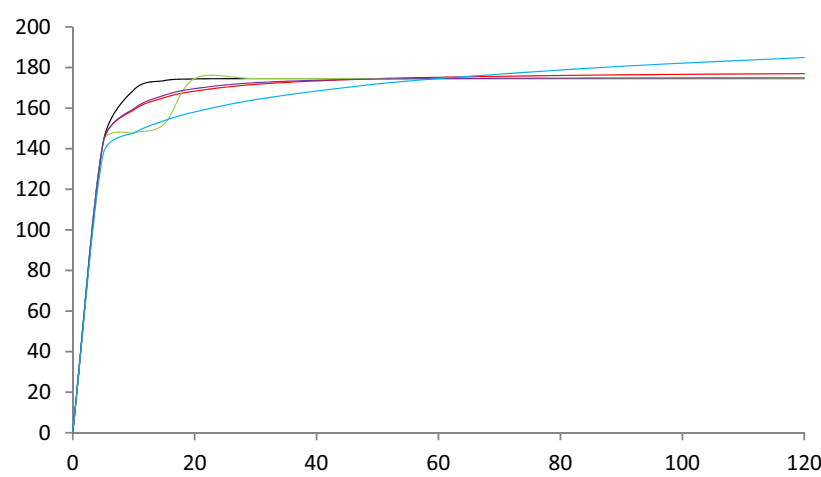

Fig. 12 Comparison between selected kinetic models and experimental adsorption data obtained for $\mathrm{Cd}(\mathrm{II})$ ion adsorption on malonic acid treated camelthornat $30{ }^{\circ} \mathrm{C}$ (). Pseudo-first-order (black), pseudosecond-order (red), intra-particle (green), Bangham (purple), Elovich (blue)

\section{Adsorption Mechanism}

The removal of Cd(II) ions from solution onto MATC can be described by three mechanisms. The first is exchange of $\mathrm{Cd}$ (II) ions with $\mathrm{H}^{+}$associated with the carboxylic acid moieties present in MATC, which result from the thermal treatment of camelthorn biomass with malonic acid, this is consistent with the data obtained from $\mathrm{pH}$ and $\mathrm{pH}_{\mathrm{PZC}}$. The second is intra-particle diffusion control involving (a) movement of the adsorbate from bulk solution to the sorbent surface, (b) diffusion of the adsorbate through the boundary layer to the sorbent surface, (c) adsorption of Cd(II) ions on sorbent surface active sites, and (d) intra-particle diffusion of the $\mathrm{Cd}(\mathrm{II})$ ions into the internal pores of the sorbent. Finally, chelation (complexation) may occur between the $\mathrm{Cd}(\mathrm{II})$ ions, which are electron-accepting in character, and electron-donating species, e.g. oxygen-rich moieties of the sorbent surface (Scheme 2) [19].

\section{Conclusions}

Camelthorn biomass were modified by thermally-driven reaction with malonic acid to create malonic acid treated camelthorn (MATC) sorbents. The process was shown to be affected by malonic acid concentration, dehydration time and temperature, allowing an optimal sorbent to be obtained, which was characterised for textural, morphological and chemical structure. The sorbent showed a rough aggregated surface with little available surface area $\left(1.3 \mathrm{~m}^{2} \mathrm{~g}^{-1}\right)$, and increased active surface groups upon reaction with malonic acid. MATC sorbents were utilised for adsorption of $\mathrm{Cd}(\mathrm{II})$ ions from water; the results indicate that uptake of $\mathrm{Cd}$ (II) ions on MATC was affected by $\mathrm{pH}$, sorbent concentration, exposure time, and initial metal ion concentration. Isothermal analysis using eight isotherm models with either two or three parameters, showed the Langmuir model to provide the most appropriate description of the isothermal data, allowing a maximum uptake of $582.6 \mathrm{mg} \mathrm{g}^{-1}$ to be determined. The kinetics of adsorption were analysed using five kinetic models, including those with diffusional bases; overall a pseudo-second-order model best descried the adsorption

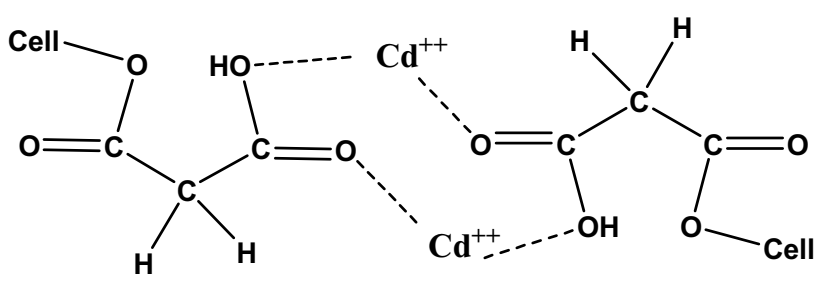

Scheme 2 Proposed complexation structure formed between malonic acid treated camelthorn biomass and $\mathrm{Cd}(\mathrm{II})$ ions. 
kinetics, indicating that the process experiences chemical control, likely a combination of ion exchange, diffusion from the bulk to the internal structure of the sorbent and, finally, surface complexation of Cd(II) ions on MATC. The high uptake and low equilibration time, of less than $20 \mathrm{~min}$, indicates that this material has potential for heavy metal remediation from water courses.

Open Access This article is licensed under a Creative Commons Attribution 4.0 International License, which permits use, sharing, adaptation, distribution and reproduction in any medium or format, as long as you give appropriate credit to the original author(s) and the source, provide a link to the Creative Commons licence, and indicate if changes were made. The images or other third party material in this article are included in the article's Creative Commons licence, unless indicated otherwise in a credit line to the material. If material is not included in the article's Creative Commons licence and your intended use is not permitted by statutory regulation or exceeds the permitted use, you will need to obtain permission directly from the copyright holder. To view a copy of this licence, visit http://creativecommons.org/licenses/by/4.0/.

\section{References}

1. Langmuir I (1916) The constitution and fundamental properties of solids and liquids. J Am Chem Soc 38:2221-2295

2. Arancibia-Miranda N, Silva-Yumi J, Escudey M (2015) Effect of cations in the background electrolyte on the adsorption kinetics of copper and cadmium and the isoelectric point of imogolite. $\mathrm{J}$ Hazard Mater 299:675-684

3. Bujn Z, Baláz P, Zorkovská A, Danková Z, Brianc J (2015) Adsorption of cadmium (II) on waste biomaterial. J Colloid Interface Sci 454:121-133

4. Yadaei H, Beyki MH, Shemirani F, Nouroozi S (2018) Ferrofluid mediated chitosan@mesoporous carbon nanohybrid for green adsorption/preconcentration of toxic Cd(II): Modeling, kinetic and isotherm study. React Funct Polymers 122:85-97

5. Hashem A, Hussein HA, Sanousy MA, Adam E, Ayoub A (2013) Bioadsorption of Cd (II) from contaminated water on treated sawdust: adsorption mechanism and optimization. J Water Res Protect 5:82-90

6. Gusain D, Srivastava V, Sharma YC (2014) Kinetic and thermodynamic studies on the removal of $\mathrm{Cu}$ (II) ions from aqueous solutions by adsorption on modified sand. J Ind Eng Chem 20:841-847

7. Falayi T, Ntuli F (2014) Removal of heavy metals and hromateation of acid mine drainage with un-activated attapulgite. J Ind Eng Chem 20:1285-1292

8. Janin A, Blais JF, Mercier G, Drogui P (2009) Selective recovery of $\mathrm{Cr}$ and $\mathrm{Cu}$ in leachate from hromate copper arsenate treated wood using chelating and acidic ion exchange resins. J Hazard Mater 169(1-3):1099-1105

9. Bratskaya SY, Pestov AV, Yatluk YG, Avramenko VA (2009) Heavy metals removal by flocculation/precipitation using N-(2-carboxyethyl) chitosans. Colloids Surf A Physicochem Eng Asp 339:140-144

10. Tran TK, Leu HJ, Chiu KF, Lin CY (2017) Electrochemical treatment of heavy metal containing wastewater with the removal of COD and heavy metal ions. J Chin Chem Soc 64:493-502

11. Cséfalvay E, Pauer V, Mizsey P (2009) Recovery of copper from process waters by nanofiltration and reverse osmosis. Desalination 240(1-3):132-142
12. Naushad M, Vasudevan S, Sharma G, Kumar A, Alothman ZA (2016) Adsorption kinetics, isotherms, and thermodynamic studies for $\mathrm{Hg}++$ adsorption from aqueous medium using alizarin red-S-loaded amberlite IRA-400 resin. Desalin Water Treat 57(39):18551-18559

13. Hashem A, Badawy S (2015) Sesbania sesban L biomass as a novel sorbent for removal of $\mathrm{Pb}$ (II) from contaminated water: non-linear and error analysis. Green Process Synth 4:179-190

14. Hashem A, Hammad Hamdy A, Al-Anwar A (2016) Modified camelorum tree particles as a new sorbent for adsorption of $\mathrm{Hg}$ (II) from aqueous solutions: kinetics, thermodynamics and nonlinear isotherms. Desalin Water Treat 57(50):1-17

15. A. Hashem, Hamdy A. Hammad and A.Al-Anwar. (2015). Chemically Modified Retama raetam Biomass as a New Sorbent for $\mathrm{Pb}$ (II) Ions from Aqueous Solution: Non-Linear Regression, Kinetics and Thermodynamics. Green Process Synth 463-478.

16. Hashem A, Alaa Al-Anwar DM, Hussein NM, Nagy S. Eisa (2016) Isotherms and kinetic studies on biadsorption of $\mathrm{Hg}$ (II) ions onto ziziphus spina-christi L. from aqueous solutions. Green Process Synth 5(2):213-224

17. Tang C, Brodie P, Brunsting M, Tam KC (2020) Carboxylated cellulose cryogel beads via a one-step ester crosslinking of maleic anhydride for copper ions removal. Carbohydr Polymers 242:116397

18. Chen J, Li H, Fang C, Cheng Y, Han H (2020) Synthesis and structure of carboxymethylcellulose with a high degree of substitution derived from waste disposable paper cups. Carbohydr Polymer 237:116040

19. Hashem A, Badawy SM, Farag S, Mohamed LA, Fletcher AJ, Taha GM (2020) Non-linear adsorption characteristics of modified pine wood sawdust optimised for adsorption of $\mathrm{Cd}$ (II) from aqueous systems. J Environ Chem Eng 8:103966

20. Hashem A, Fletcher AJ, El-Sakhawy M, Mohamed LA, Farag S (2020) Aminated hydroximoyl camelthorn residues as a novel sorbent for extracting $\mathrm{Hg}$ (II) from contaminated water: studies of isotherm, kinetics, and mechanism. J Polymers Environ 28(9):1-13

21. Khalil MI, Hashem A, Hebeish A (1990) Caboxymethylation of maize starch. Starch 42(2):60-63

22. Brunauer S, Emmett PH, Teller E (1938) Adsorption of gases in multimolecular layers. J Am Chem Soc 60(2):309-319

23. Lippens BC, De Boer JH (1965) Studies on pore systems in catalysts: V The t method. J Catal 4(3):319-323

24. F. Rouquerol, J. Rouquerol, K. S. W. Sing. (1999). Assessment of mesoporosity. Freundlich, H. (1906). Over the adsorption in solution. J Phys Chem 385-470

25. Barrett EP, Joyner LG, Halenda PP (1951) The determination of pore volume and area distributions in porous substances I Computations from nitrogen isotherms. J Am Chem Soc 73(1):373-380

26. A.Kapoor, R.T. Yang. (1989). Correlation of equilibrium adsorption data of condensable vapours on porous sorbents. Gas Sep Purif 187-192

27. Vijayaraghavan K, Padmesh TVN, Palanivelu K, Velan M (2006) Biosorption of nickel(II) ions onto Sargassum wightii: application of two-parameter and three-parameter isotherm models. J Hazard Mater 133(1-3):304-308

28. El-Sakhawy M, Kamel S, Salama A, Tohamy HAS (2018) Preparation and infrared study of cellulose based amphiphilic materials. Cellul Chem Technol 52(3-4):193-200

29. Yuan W, Cheng J, Huang H, Xiong S, Gao J, Zhang J, Feng S (2019) Optimization of cadmium biosorption by Shewanella putrefaciens using a Box-Behnken design. Ecotox Ecotox Environ Save 175:138-147 
30. F. Noli, E. Kapashi, M. Kapnisti. (2019). Biosorption of uranium and cadmium using sorbents based on Aloe vera wastes. J Environ Chem Eng 102985

31. Song T, Liang J, Bai X, Li Y, Wei Y, Huang S, Dong L, Qu J, Jin Y (2017) Biosorption of cadmium ions from aqueous solution by modified Auricularia Auricular matrix waste. J Mol Liq 241:1023-1031

32. Kong S, Huang X, Li K, Song X (2019) Adsorption/desorption isotherms of $\mathrm{CH} 4$ and $\mathrm{C}_{2} \mathrm{H}_{6}$ on typical shale samples. Fuel 255:115632

33. Koopal L, Tan W, Avena M (2019) Mixed ad/desorption kinetics unraveled with the equilibrium adsorption isotherm. Colloids Surf A: Physicochem Eng Aspects 577:709-722

34. Tan G, Xiao D (2009) Adsorption of cadmium ion from aqueous solution by ground wheat stems. J Hazard Mater 164(2-3):1359-1363

35. Hamdaoui O (2006) Batch study of liquid-phase adsorption of methylene blue using cedar sawdust and crushed brick. J Hazard Mater 135(1-3):264-273

36. Ngah WWL, Teong R, Toh MH (2012) Utilization of chitosanzeolite composite in the removal of $\mathrm{Cu}$ (II) from aqueous solution: adsorption, desorption and fixed bed column studies. Chem Eng J 209:46-53

37. Saraeian A, Hadi A, Raji F, Ghassemia A, Johnson M (2018) Cadmium removal from aqueous solution by low-cost native and surf 559 ace modified Sorghum x drummondii (Sudangrass). J Environ Chem Eng. https://doi.org/10.1016/J.JECE.2018.05.018

38. Martín-Lara M, Hernáinz F, Calero M, Blázquez G, Tenorio G (2009) Surface chemistry evaluation of some solid wastes from olive-oil industry used for lead removal from aqueous solutions. Biochem Eng J 44(2-3):151-159

39. Chen HY, Zhao A. Wang (2007) Removal of $\mathrm{Cu}$ (II) from aqueous solution by adsorption onto acid-activated palygorskite. J Hazard Mater 149(2):346-354

40. Langmuir I (1916) The constitution and fundamental properties of solids and liquids. Part I. Solids. J Am Chem Soc 38(11):2221-2295

41. Freundlich H (1907) Über die adsorption in lösungen. Z Phys Chem 57(1):385-470

42. Redlich O, Peterson DL (1959) A useful adsorption isotherm. J Phys Chem 63(6):1024-1026

43. Toth V (1971) State equations of the solid gas interface layer. Acta Chem Acad Hung 311-317.

44. Sips R (1948) Combined form of langmuir and freundlich equations. J Chem Phys 490-495

45. Foo KY, Hameed BH (2010) Insights into the modeling ofadsorption isotherm systems. Chem Eng J 156(1):2-10
46. Khan AR, Ataullah R, Al-Haddad A (1997) Equilibrium adsorption studies of some aromatic pollutants from dilute aqueous solutions on activated carbon at different temperatures. J Colloid Interface Sci 194(1):154-165

47. Jossens L, Prausnitz JM, Fritz W, Schlünder EU, Myers AL (1978) Thermodynamics of multi-solute adsorption from dilute aqueous solutions. Chem Eng Sci 33(8):1097-1106

48. Kumar PS, Ramalingam S, Abhinaya RV, Kirupha SD, Murugesan A, Sivanesan S (2012) Adsorption of metal ions onto the chemically modified agricultural waste. Clean Soil, Air, Water 40(2):188-197

49. Li Q, Chai L, Qin W (2012) Cadmium(II) adsorption on esterified spent grain: Equilibrium modeling and possible mechanisms. Chem Eng J 197:173-180

50. Suresh C, Reddy DHK, Harinath Y, Naik BR, Seshaiah K, Reddy AVR (2014) Development of wood apple shell (Feronia acidissima) powder biosorbent and its application for the removal of Cd(II) from aqueous solution. Sci World J. https:// doi.org/10.1155/2014/154809

51. Asuquo E, Martin A, Nzerem P, Siperstein F, Fan X (2017) Adsorption of $\mathrm{Cd}(\mathrm{II})$ and $\mathrm{Pb}(\mathrm{II})$ ions from aqueous solutions using mesoporous activated carbon sorbent: equilibrium, kinetics and characterisation studies. J Environ Chem Eng 5(1):679-698

52. Lagergren SK (1898) About the theory of so-called adsorption of soluble substances. Sven Vetensk Handingarl 24:1-39

53. Ho Y-S, McKay G (1999) Pseudo-second order model for sorption processes. Process Biochem 34(5):451-465

54. Weber WJ, Morris JC (1963) Kinetics of adsorption on carbon from solution. J Sanit Eng Div 89(2):31-6

55. Marrakchi F, Ahmed M, Khanday W, Asif M, Hameed B (2017) Mesoporous-activated carbon prepared from chitosan flakes via single-step sodium hydroxide activation for the adsorption of methylene blue. Int J Biol Macromol 98:233-239

56. Kołodyńska D, Hałas P, Franus M, Hubicki Z (2017) Zeolite properties improvement by chitosan modification-sorption studies. J Ind Eng Chem 55:187-196

57. Tutem E, Apak R, Unal CF (1998) Adsorptive removal of chlorophenols from water by bituminous shale. Water Res 32(8):2315-2324

58. Chien SH, Clayton WR (1980) Application of Elovich equation to the kinetics of phosphate release and sorption in soils. Soil Sci Soc Am J 44(2):265-268

Publisher's Note Springer Nature remains neutral with regard to jurisdictional claims in published maps and institutional affiliations. 